Ivabelle M. Ducto, MD

Joseph E. Cachuela, MD

Department of Otorhinolaryngology Head and Neck Surgery

Southern Philippines Medical Center
Correspondence: Dr. Joseph E. Cachuela Department of Otorhinolaryngology Head and Neck Surgery

Southern Philippines Medical Center J.P. Laurel Ave.

Bajada, Davao City 8000

Philippines

Phone: +63 822272731 local 353

Email:j_cachuela_md@yahoo.com

The authors declared that this presents original material that is not being considered for publication or has not been published or accepted for publication elsewhere or in part, in print or electronic media; that the requirements for authorship have been met by all the authors, and the author believes that the manuscript represents honest work.

Disclosures: The authors signed a disclosure that there are no financial or other (including personal) relationship, intellectual passion, political or religious beliefs, and institutional affiliations that might led to conflict of interest.

Presented at the Philippine Society of Otolaryngology Head and Neck Surgery Analytical Research Contest. December 6, 2019. Palawan Ballroom, Edsa Shangri-La Hotel, Mandaluyong City.

\section{Effectiveness of Levodropropizine on Post-Operative Sore Throat After Endotracheal Intubation for Head and Neck Surgery: A Double-Blind Randomized Controlled Trial}

\begin{abstract}
Objective: To determine the effectiveness of levodropropizine in reducing the incidence of post-operative sore throat (POST) among ear, nose, throat, head and neck (ENT-HNS) patients undergoing general endotracheal anesthesia.
\end{abstract}

\section{Methods:}

Design: Double-Blind, Randomized, Placebo Controlled Trial

Setting: $\quad$ Tertiary Government Training Hospital

Participants: Sixty (60) ENT-HNS patients aged between 19 to 60 years old admitted to the Southern Philippines Medical Center from January to March 2019 for surgeries on benign thyroid tumors, benign submandibular gland tumors and tonsils requiring orotracheal intubation were randomized into control and treatment groups of 30 patients each.

Results: There was a statistically significant difference $(p=.0016)$ in the incidence of POST 6 hours after surgery between control $(25 / 30 ; 83 \%)$ and treatment $(16 / 30 ; 53.33 \%)$ groups. However, confounders such as length and type of surgery (more females and tonsillectomy cases in the control group) were not fully eliminated by randomization.

Conclusion: Perioperative levodropropizine significantly decreases the incidence of moderate (as well as mild) postoperative sore throat. It was not shown to decrease the incidence of severe sore throat. A larger cohort (adjusted for other confounders) may better describe the benefit of this treatment.

Keywords: levodropropizine; postoperative complications; post-operative sore throat

Post-operative sore throat (POST) is a common complication following general endotracheal intubation (GETA). ${ }^{1}$ It has an estimated incidence of as low as $14.4-30 \%{ }^{2}$ to as high as $50-90 \% .^{3-5}$ Many cases of POST resolve spontaneously in a matter of days and only a few require intervention in the form of medications. ${ }^{6,7}$ Although considered a minor complication, ${ }^{8-10}$ significant physical distress can cause overall patient discomfort postoperatively. ${ }^{11}$ Recent findings on the mechanisms of POST prompted the use of zinc, ${ }^{3}$ NSAIDS, ${ }^{4}$ magnesium,${ }^{4,5}$ steroids, ${ }^{7}$ NMDA,${ }^{12,13}$ and levodropropizine ${ }^{14-16}$ in reducing its incidence and severity. 
Levodropropizine is a non-opiate agent with peripheral tracheobronchial antitussive effect recently shown to reduce incidence and severity of POST. ${ }^{14}$ It is administered orally in syrup form making it convenient and well tolerated by patients. ${ }^{17} \quad$ Previous studies have associated the coughing reflex in the development of POST, ${ }^{18,19}$ supporting a role for the antitussive effect of levodropropizine in attenuating POST, although none of them involved surgical procedures in the head and neck. Because head and neck procedures that are more proximate to the throat may impact on POST more directly than procedures on the trunk and extremities, studies in this anatomic area are needed.

This study aims to determine the effectiveness of levodropropizine on reducing the incidence of post-operative sore throat among ear, nose, throat, head and neck patients undergoing general endotracheal anesthesia.

\section{METHODS}

With Department of Health Cluster XI Ethics Review Committee approval, 60 adult patients of the Southern Philippines Medical Center undergoing GETA for a head and neck surgery (thyroidectomy, submandibular gland excision, and tonsillectomy) from January to March 2019 were randomized by an admitting resident physician using fishbowl draw to receive levodropropizine or placebo.

The sample size to determine difference between estimated $50 \%$ POST in placebo and 15\% POST in the treatment group with an alpha error of $5 \%$ and a power of 0.80 was calculated at 25 patients per arm; and set at 30 patients per arm with a dropout rate of $20 \%$.

Excluded from the study were those with a history of gastroesophageal reflux disease (GERD); history of drug reactions after taking anti-cough or common cold medications; were pregnant; had congenital or acquired abnormalities of the upper airway such as tumor, polyp, trauma, abscess, inflammation, infection, or foreign bodies; had previous airway surgery; had increased risk of aspiration; had coagulation disorders; had previous history of difficult intubation or conditions with expected difficult airway including Mallampati classification $\geq 3$ or thyromental distance $<6.5 \mathrm{~cm}$; had symptoms of sore throat or upper respiratory tract infection; were expected to need (or who needed) a nasogastric tube during the perioperative period; used other intubation devices beyond direct laryngoscopy such as a lighted stylet or fiberoptic bronchoscopy; and who required nasotracheal intubation.

Initial data collected included age, gender, and smoking history (as a risk factor for sore throat). The treatment group received $15 \mathrm{ml}$ of levodropropizine syrup one hour prior to induction. The placebo group received an equivalent amount of sucrose solution syrup. The treatment and placebo were administered by a pre-assigned resident physician, keeping the investigators, surgeons, nurses, and patients blinded to treatment allocation. No sedative drugs were given preoperatively.
Routine anesthesia induction procedures were observed by an anesthesiologist also blinded to treatment allocation. Standard cuffed endotracheal tubes (ETT) lubricated with K-Y ${ }^{\circ}$ Jelly (Reckitt Benckiser Group, Slough, England) were used, with the size of endotracheal tube used during each procedure recorded. Standard laryngoscopes with 3 or 4 Macintosh metal blades were utilized as needed. After intubation, the cuff was inflated until no air leakage was heard, with peak airway (intracuff) pressure maintained between 20-22 cm $\mathrm{H}_{2} \mathrm{O}$ using the Rusch $^{\circ}$ EndoTest $^{\mathrm{m}}$ (Teleflex Inc. Morrisville, NC, USA) handheld cuff pressure manometer. No nasogastric tube was inserted in any patient. After the surgical procedure, anesthesia administration was terminated.

Upon emergence from anesthesia, adequate spontaneous ventilation and response to verbal commands were confirmed, gentle oropharyngeal suctioning of oral secretions using a soft rubber catheter was performed to minimize injury to tissues in the oral cavity then tracheal extubation was immediately performed. After extubation, all patients were transferred to the post-anesthesia care unit.

Intraoperative variables recorded and collected included duration of anesthesia, duration of surgery, ASA-PS classification, inhalational anesthetic, number of attempts at laryngoscopy, traumatic laryngoscopy, number of attempts at intubation, presence of blood in the secretions or the tube, size of endotracheal tube, initial cuff pressure, bucking and coughing upon intubation, and extubation.

In the wards, POST assessment was performed by resident evaluators who were also blinded to treatment allocation at 6 hours, 24 hours, 48 hours and 72 hours. The severity of POST was graded on a four-point scale $(0-3)$ as follows: 0 , no sore throat; 1 , mild sore throat (complained of sore throat only upon inquiry); 2 , moderate sore throat (complained of sore throat on his/her own); and 3, severe sore throat (change of voice or hoarseness, associated with throat pain).

Continuous variables were summarized as means \pm SD and compared using Independent Sample t-test. Categorical variables were summarized using frequencies and percentages and compared using Chi-square with Yates' correction and Fisher exact tests if the contingency table had a value less than 1 . A value of $p<.05$ was considered significant. Absolute and relative risk reduction were determined with an intention to treat analysis.

As secondary analysis, we also compared the groups on severity of POST at 6, 24, 48 and 72 hours after surgery. In this stratified analysis, the groups were compared separately using presence or absence of mild, moderate, or severe POST (binomial) as categorical dependent variable, and study drug (levodropropizine versus placebo) as independent variable.

\section{RESULTS}

A total of 60 patients, 30 each in the control and treatment groups, completed the study. Their ages ranged between 19 to 60 years old, with a control group mean age of $34.10(S D \pm 8.68)$ and treatment 


\section{ORIGINAL ARTICLES}

group mean age of 35.47 (SD \pm 10.34 ). There was no significant difference between both groups in terms of age $(p=.5815)$. There were 24 males and 36 females; with a female to male ratio of $20: 10(66.7 \%)$ in the control group, and 16:14 (53.33\%) in the treatment group. Although there were more females in the placebo group, there was no significant difference in gender ratio between the two groups ( $p=.1679)$.

There were $8 / 30(26.67 \%)$ with a history of smoking in the control group, and $4 / 30(13.33 \%)$ in the treatment group, but there was no statistically significant difference between the two groups $(p=.564)$. A total of 44 underwent thyroidectomy (20 controls, 24 treatment), 6 underwent submandibular gland excision (3 controls, 3 treatment), and 10 underwent bilateral tonsillectomy (7 controls, 3 treatment). Having more tonsillectomy cases randomized to the placebo group was statistically significant $(p=.0)$.

Multiple t-test analyses were performed on intraoperative variables summarized in Table 1. There were no significant differences between control $(M=277.79, S D=115.29)$ and treatment $(M=272.2, S D=92.54)$ groups in terms of duration of anesthesia administration $\mathrm{t}(\mathrm{n}-1)=.85, \mathrm{p}$ $=.55$. There were no significant differences between control $(M=225.5$, $S D=121.37)$ and treatment $(M=235.84, S D=90.91)$ groups in terms of duration of surgical procedures $(p=.6)$. The anesthetic administered to all patients in both groups was sevoflourane and all patients underwent atraumatic laryngoscopy. There were no significant differences between control $(M=1.04, S D=.18)$ and treatment $(M=1.04, S D=$ .18) groups in terms of attempts at laryngoscopy $t(n-1)=.94, p=.52$ and there were no significant differences between control $(M=1, S D$ $=0)$ and treatment $(M=1.04, S D=.18)$ groups in terms of intubation attempts $t(n-1)=.33, p=.8$ either. There was no significant difference between control $(M=7.16, S D=.4)$ and treatment group $(M=7, S D=$ .32 ) in terms of size of ETT inserted $t(n-1)=.13, p=.92$. There was no significant difference in the initial cuff pressure applied in control group $(\mathrm{M}=20.5, \mathrm{SD}=.9)$ and treatment group $(\mathrm{M}=20.24, \mathrm{SD}=.69)$ with $\mathrm{t}$ $(n-1)=.23, p=.86)$. There was no bucking or coughing reported on intubation and during extubation among all patients in both groups. No adverse events were noted in both treatment and control groups.

Most of the patients included in the study were classified as ASA I ( $n=48$ ), with 25 controls and 23 in the treatment group. There were 12 classified as ASA II; 5 controls and 7 in the treatment group. Chi-square test revealed no significant difference between the two groups $x^{2}(1$, $\mathrm{N}=60) 0.42, \mathrm{p}=.52$ ).

Blood in the secretions or in the ET tube was only reported in 11 patients (6/30 controls and 5/30 in the treatment group). Chi-Square test revealed no significant difference between control and treatment groups $\left.x^{2}(1, N=60) 0.11, p=.74\right)$.

Table 2 summarizes the distribution of patients with POST at 6 , 24,48 , and 72 hours for control and treatment groups. At six hours postoperatively, there was a statistically significant difference $(p=$ .002 ) in the number of patients who developed moderate POST among control (15 patients; 50\%) and treatment (4 patients; 13\%) groups.
Table 1. Intraoperative Variables and Frequency Distribution

\begin{tabular}{|l|c|c|c|}
\multicolumn{1}{|c|}{ Variables } & $\begin{array}{c}\text { Control } \\
\text { (n= 30) }\end{array}$ & $\begin{array}{c}\text { Levodropropizine } \\
\text { (n= 30) }\end{array}$ & $\mathbf{p}$-Value \\
\hline Duration of anesthesia (min) & 277.8 & 272.2 & .552167 \\
\hline Duration of surgery (min) & 225.5 & 235.8 & .600501 \\
\hline $\begin{array}{l}\text { Inhalation anesthetic } \\
\text { (des/iso/sevo) }\end{array}$ & Sevoflourane & Sevoflourane & 1 \\
\hline $\begin{array}{l}\text { Number of attempts at } \\
\text { laryngoscopy }\end{array}$ & 1 & 1 & .520827 \\
\hline Traumatic laryngoscopy & 0 & 0 & 1 \\
\hline $\begin{array}{l}\text { Number of attempts of } \\
\text { intubation }\end{array}$ & 1 & 1 & .798638 \\
\hline Size of ETT & 7 & 7 & .916817 \\
\hline $\begin{array}{l}\text { Initial cuff pressure } \\
\text { (cm H2O) }\end{array}$ & 20.5 & 20.2 & .857274 \\
\hline $\begin{array}{l}\text { Bucking or coughing on } \\
\text { intubation }\end{array}$ & 0 & 0 & 1 \\
\hline $\begin{array}{l}\text { Bucking or coughing on } \\
\text { extubation }\end{array}$ & 0 & 0 & 1 \\
\hline
\end{tabular}

There was no significant difference noted in the number of patients who developed mild POST, 5 (16.7\%) versus 4 (13\%) in the control and treatment groups ( $p=.72$ ). Interestingly, the percentage of patients who reported severe POST was much higher in the treatment than in the control arm, $8(26 \%)$ versus $5(16.7 \%)$ although this was not statistically significant $(p=.36)$.

At 24 hours postoperatively, there was a statistically significant difference $(p=.004)$ in the number of patients who reported moderate POST, with 7 (23\%) controls and none from the treatment group. More patients from the control group $9(30 \%)$ also reported mild POST compared to $5(16.7 \%)$ patients in the treatment group, but this was not statistically significant $(p=.23)$. However, a reverse pattern was noted among patients who reported severe POST, with only $5(16.7 \%)$ in the control group compared to $8(26.7 \%)$ in the treatment group, although there was no significant difference $(p=.39)$.

At 48-hours postoperatively, significant statistical differences were noted between control and treatment groups for the number of patients who reported mild $(p=.01)$ and moderate $(p=.04)$ POST. In the control group, $10(33 \%)$ and 4 (13\%) patients reported mild and moderate POST respectively, in contrast to only 2 (6.7\%) and zero (0) patients in the who reported mild and moderate POST, respectively, in the treatment group. While there were more patients $(8,26.7 \%)$ who reported severe POST in the treatment group after 48 hours, no statistically significant differences were noted when compared with 3 $(10 \%)$ in the control group $(p=.11)$.

At 72-hours postoperatively, there were 8 (26.7\%) and 4 (13\%) patients who reported mild and moderate POST in the control group compared to none (0) in the treatment group; and this difference was statistically significant $(p=.002 ; p=.04)$. Among those who reported 
ORIGINAL ARTICLES

severe POST, 3 (10\%) patients were from the control group while 8 $(26.7 \%)$ were in the treatment group. However, there was no statistically significant difference $(p=.098)$. These same eight patients $(26.7 \%)$ in the treatment group consistently reported severe POST at 6, 24, 48 and 72 hours.

Table 2. Frequency Distribution of Patients with Postoperative Sore Throat at 6 Hours, 24 Hours, 48 Hours and 72 Hours

\begin{tabular}{|c|c|c|c|}
\hline Time frame & $\begin{array}{l}\text { Control, } n(\%) \\
(n=30)\end{array}$ & \begin{tabular}{|} 
Levodropropizine, \\
$n(\%)(n=30)$
\end{tabular} & p-value \\
\hline \multicolumn{4}{|l|}{6 hours } \\
\hline Mild & $5(16.7)$ & $4(13.0)$ & $.72(.723235)$ \\
\hline Moderate & $15(50.0)$ & $4(13.0)$ & $<.01(.001835)$ \\
\hline Severe & $5(16.7)$ & $8(26.7)$ & $.36(.355617)$ \\
\hline POST & $25(83.3)$ & $16(53.33)$ & .026 \\
\hline \multicolumn{4}{|l|}{24 hours } \\
\hline Mild & $9(30.0)$ & $5(16.7)$ & $.23(.229058)$ \\
\hline Moderate & $7(23.0)$ & 0 & $<.01(.004316)$ \\
\hline Severe & $5(16.7)$ & $8(26.7)$ & $.40(.391261)$ \\
\hline POST & $21(70.0)$ & $13(43.0)$ & .068 \\
\hline \multicolumn{4}{|l|}{48 hours } \\
\hline Mild & $10(33.0)$ & $2(6.7)$ & $<.01(.009253)$ \\
\hline Moderate & $4(13.0)$ & 0 & $.04(.035528)$ \\
\hline Severe & $3(10.0)$ & $8(26.7)$ & $.11(.11125)$ \\
\hline POST & $17(56.7)$ & $10(33.3)$ & .119) \\
\hline \multicolumn{4}{|l|}{72 hours } \\
\hline Mild & $8(26.7)$ & 0 & $<.01(.001938)$ \\
\hline Moderate & $4(13.0)$ & 0 & $.04(.038983)$ \\
\hline Severe & $3(10.0)$ & $8(26.7)$ & $.10(.098417)$ \\
\hline POST & $15(50.0)$ & $8(26.7)$ & .111 \\
\hline
\end{tabular}

In this study, there were a total of 12 patients with a history of tobacco smoking. On post randomization, 8 patients were randomly assigned to the control group while 4 were in the treatment group. Post-operative sore throat was present in all 8 control group patients with varying degrees of severity and in 3 of 4 patients in the treatment group. Among the non-smokers, 26 patients were randomly assigned to the treatment group while 22, were in the control group. Among those in the treatment group, 14 developed POST (54\%) compared to 19 out of 22 controls (86\%). There was no statistically significant relationship between smoking history and the incidence of POST ( $p=.61)$.

Of 10 patients who underwent tonsillectomy, seven were randomized to the control group and three to the treatment group. All seven controls developed POST, compared to two out of three in the treatment group, although this was not statistically significant $(p=.36)$.

Stratified comparisons between proportions of POST done at 6, 24, 48 and 72 hours with estimates for absolute risk reductions (ARR) and numbers needed to treat (NNT) at $95 \%$ confidence intervals (Cl) revealed that there was a significant difference between treatment and control groups at 6 hours post-surgery $\left(X^{2}=4.929 ; p=.026 ;\right.$ ARR $=0.3$ [0.064 to 0.496]; NNT = 3 [16 to 2]). However, there was no clear difference between treatments at 24 hours post-surgery $\left(X^{2}=3.326 ; p=\right.$ .068; $A R R=0.267$ [0.017 to 0.475 ]; NNT $=4$ [60 to 2]), at 48 hours postsurgery $\left(X^{2}=2.424 ; p=.119 ; A R R=0.233[-0.017\right.$ to 0.446$] ; N N T=4$ [-60 to 2]) and at 72 hours post-surgery $\left(X^{2}=2.538 ; p=.111 ; A R R=0.233\right.$ [-0.012 to 0.443$] ;$ NNT $=4$ [-86 to 2]). (Table 3 )

Table 3. Frequency Distribution of POST Between Placebo and Levodropropizine

\begin{tabular}{|c|c|c|c|c|c|c|c|c|}
\hline $\begin{array}{c}\text { Evaluation } \\
\text { time }\end{array}$ & $\begin{array}{c}\text { Control } \\
(\mathbf{n = 3 0 )}\end{array}$ & $\begin{array}{c}\text { Treatment } \\
(\mathbf{n = 3 0 )}\end{array}$ & $\begin{array}{c}\text { Relative } \\
\text { Risk }\end{array}$ & $\begin{array}{l}\text { Odds } \\
\text { Ratio }\end{array}$ & $\mathbf{9 5 \%}(\mathbf{C L})$ & NNT & ARR & $\begin{array}{c}\mathbf{p} \\
\text { value }\end{array}$ \\
\hline $6 \mathrm{H}$ & $25(83.3 \%)$ & $16(53.3 \%)$ & 1.56 & 4.38 & $3(0.77,5.27)$ & 3.3 & 0.2997 & .026 \\
\hline $24 \mathrm{H}$ & $21(70.0 \%)$ & $13(43.0 \%)$ & 1.62 & 3.05 & $2.7(1.02,4.31)$ & 3.7 & 0.27 & .068 \\
\hline $48 \mathrm{H}$ & $17(56.7 \%)$ & $10(33.3 \%)$ & 1.7 & 2.62 & $2.3(0.28,4.39)$ & 4.3 & 0.234 & .119 \\
\hline $72 \mathrm{H}$ & $15(50.0 \%)$ & $8(26.7 \%)$ & 1.88 & 2.75 & $2.3(0.39,4.28)$ & 4.3 & 0.233 & .111 \\
\hline
\end{tabular}

\section{DISCUSSION}

Our study demonstrated that treatment with $15 \mathrm{ml}$ of levodropropizine administered 1 hour before surgery reduced the incidence of moderate POST after general anesthesia with orotracheal intubation. At 6 hours post-surgery, the absolute risk reduction is $30 \%$ [confidence interval 6 to 50\%] and the number needed to treat is 3 . The differences for mild POST were also evident but less pronounced, being only significant at 48 and 72 hours after surgery. That POST generally decreases as time interval from surgery to POST reassessment increases may be attributed to post-operative medications, healing and decreased swelling. However, because patients manifesting severe POST minimally decreased in number even in the treatment group might suggest that severe POST requires supplementary medications and may further suggest that the effect of levodopropizine is clinically and statistically significant in alleviating POST mostly during the first 6 hours post-surgery. Moreover, the distribution of mild, moderate and severe POST between treatment and control groups over time did not show any decrease in severity of POST.

A previous study by Rashwan et al. ${ }^{2}$ evaluated the efficacy of tramadol gargle in POST and concluded that preoperative gargling with tramadol reduced the incidence and severity of POST. Farhang and Grondin ${ }^{3}$ studied the effectiveness of zinc lozenges in POST and found that administration of a single preoperative dose of $40-\mathrm{mg}$ zinc lozenges is effective to reduce POST. In another study, Borazan et al. ${ }^{5}$ showed that giving preoperative oral magnesium lozenge is effective in reducing both incidence and severity of POST. In all of these studies however, the patients enrolled underwent orthopedic surgeries or urological surgeries and no head and neck surgeries were included.

Although the average duration of anesthesia exposure was slightly longer in the control group (277 minutes) compared with the treatment group (272 minutes), there was no statistically significant difference. 


\section{ORIGINAL ARTICLES}

Likewise, the duration of surgery did not differ significantly between control (225 minutes) in and treatment (235 minutes) groups. The number of attempts at laryngoscopy as well as initial cuff pressures were not significantly different either, and no bucking or coughing were noted for intubation and extubation in all patients.

In the previous studies, the researchers suggested that effectiveness of the administered drugs in the reduction of incidence and severity of POST was due to the anti-inflammatory effects of the medications. The mode of action of levodropropizine may be related to diminished pharyngeal movement that can trigger pain. Levodropropizine is a racemic non-opiate antitussive agent and acts through a mainly peripheral tracheobronchial antitussive effect by inhibition of vagal C-fiber and its sensor neuropeptide. ${ }^{15}$ The reduction in C fiber activation may dampen coughing reflexes stimulated by ETT insertion, ${ }^{18}$ reducing and perhaps preventing POST among the patients in the treatment group.

Interestingly, all of the 8 patients who scored severe POST in the treatment group consistently reported severe POST in all time measurements. Among these patients ( 4 females, 4 males), 7 underwent thyroidectomy and 1 underwent tonsillectomy and 2 of the patients claimed to have a history of smoking. However, in this research, these findings are not sufficient to support that gender, smoking and type of surgery are risk factors for development of severe POST.

Although levodropropizine exhibits considerably lower central nervous system (CNS) depressant effects than other opiate antitussives and is least likely to cause sedation in treated patients, ${ }^{15}$ several adverse drug reactions include vomiting, abdominal pain, diarrhea, ${ }^{16}$ and allergic reactions. ${ }^{20}$ Because these adverse effects are generally similar to other antitussive and anesthetic medications, we were not concerned in using levodropropizine as a treatment. Fortunately, none of these effects were seen among our patients.

This study has several limitations. First the number of enrolled patients per procedure was relatively small. The head and neck surgical procedures included were not stratified according to type due to the limited number of cases. A study limited to only one type of head and neck surgical procedure may reduce intervening factors affecting POST. This may particularly apply to the small number of patients who underwent tonsillectomy. Because tonsillectomy inherently causes sore throat, a separate study including only patients for tonsillectomy is recommended. This study succeeded in showing the effectiveness of levodropropizine in decreasing the incidence, but not the severity of POST. Future studies can address this variable, including extended time measurements to days to further evaluate the progression of POST. A larger cohort (adjusted for other confounders) may better describe the benefit of levodropropizine for POST.

In conclusion, levodropropizine administered an hour before surgery significantly decreases the incidence (but not the severity) of moderate (as well as mild) post-operative sore throat among head and neck surgery patients undergoing general endotracheal anesthesia. It was not shown to decrease the incidence of severe sore throat in this study.

\section{REFERENCES}

1. Kalil DM, Silvestro LS, Austin PN. Novel preoperative pharmacologic methods of preventing postoperative sore throat due to tracheal intubation. AANA J. 2014 Jun; 82(3):188-97. PubMed PMID: 25109156.

2. Rashwan S, Abdelmawgoud A, Badawy AA. Effect of tramadol gargle on postoperative sore throat: a double blinded randomized placebo controlled study. Egyptian Journal of Anaesthesia. 2014 Jul; 30(1): 235-239. DOI: https://doi.org/10.1016/j.egja.2014.01.010.

3. Farhang $B$, Grondin L. The effect of zinc lozenge on postoperative sore throat: a prospective randomized, double-blinded, placebo-controlled study. Anesth Analg. 2018 Jan; 126(1):78-83. DOI: 10.1213/ANE.0000000000002494: PubMed PMID: 28953493.

4. Chattopadhyay S, Das A, Nandy S, RoyBasunia S, Mitra T, Halder PS, et al. Postoperative sore throat prevention in ambulatory surgery: a comparison between preoperative aspirin and magnesium sulfate gargle - a prospective, randomized, double-blind study. Anesth Essays Res. Jan-Mar 2017; 11(1):94-100. DOI: 10.4103/0259-1162.186602; PubMed PMID: 28298764 PubMed Central PMCID: PMC5341650

5. Borazan $\mathrm{H}$, Kececioglu A, Okesli S, Otelcioglu S. Oral magnesium lozenge reduces postoperative sore throat; randomized, prospective, placebo-controlled study. Anesthesiology $2012 \mathrm{Sep}$ 117(3):512-8. DOI: 10.1097/ALN.0b013e3182639d5f; PubMed PMID: 22797283.

6. Hisham AN, Roshilla H, Amri N, Aina EN. Post-thyroidectomy sore throat following endotracheal intubation. Anz J. Surg. 2001Nov; 71(1) 669-671. DOl: 10.1046/j.1445-1433.2001.02230.x; PubMed PMID: 11736830

7. Cho CK, Kim JE, Yang HJ, Sung TY, Kwon HU, Kang PS. The effect of combining lidocaine with dexamethasone for attenuating postoperative sore throat, cough, and hoarseness. Anesthesia Pain Med. 2016 Jan; 11(1): 42-48. DOI: 10.17085/apm.2016.11.1.42.

8. Lee JY, Sim WS, Kim ES, Lee SM, Kim DK, Na YR, et al. Incidence and risk factors of postoperative sore throat after endotracheal intubation in Korean patients. J Int Med Res. 2017 Apr; 45(2):744752. DOI: 10.1177/0300060516687227; PubMed PMID: 28173712; PubMed Central PMCID: PMC5536682.

9. El-Boghdadly K, Bailey CR, Wiles MD. Postoperative sore throat: a systematic review. Anaesthesia. 2016 Jun; 71(6):706-17. DOI: 10.1111/anae.13438; PubMed PMID: 27158989.

10. Biro P, Seifert B, Pasch T. Complaints of sore throat after tracheal intubation: a prospective evaluation. University of Zurich: Zurich Open Repository and Archive. Eur J Anaesthesiol. 2005 Apr; 22(4):307-11. DOI: 10.1017/s0265021505000529; PubMed PMID: 15892411.

11. Kadri IA, Khanzada TW, Samad A, Memon W, Irfan D, Kadri A. Post-thyroidectomy sore throat: A common problem. Pak J Med Sci. 2009 Jul; 25(3): 408-412.

12. Almazan NA. Benzydamine HC10.15 percent for the oropharyngeal diseases and surgeries: a review of clinical trials. Health Research and Development Information Network. Journal. Manila Central University-Filemon D. Tanchoco Medical Foundation. 2009; 42(1) 37-42.

13. Aigbedia SO, Tobi KU, Amadasun FE. A comparative study of ketamine gargle and lidocaine jelly application for the prevention of postoperative throat pain following general anesthesia with endotracheal intubation. Niger J Clin Pract. 2017 Jun; 20(6):677-685. DOI: 10.4103/11193077.208960: PubMed PMID: 28656921.

14. Zanasi A, Lanata L, Fontana G, Saibene F, Dicpinigaitis P. De Blasio F. Levodropropizine for treating cough in adult and children: a meta-analysis of published studies. Multidiscip Respir Med. 2015 May 31; 10(1):19. DOI: 10.1186/s40248-015-0014-3; PubMed PMID: 26097707; PubMed Central PMCID: PMC4472410.

15. Mannini C, Lavorini F, Zanasi Alessandro, Saibene F, Lanata L, Fontana G. A randomized clinical trial of levodropropizine effect on respiratory centre output in Patients with intractable chronic cough: preliminary results. Chest. 2017 Jun; 151(6):1288-1294. DOI: 10.1016/j.chest.2017.02.001 PubMed PMID: 28192113

16. Banderali G, Riva E, Fiocchi A Cordaro Cl, Giovannini M. Efficacy and Tolerability of Levodropropizine and Dropropizine in Children with Non-productive Cough. J Int Med Res. MayJun 1995; 23(3):175-83. DOI: 10.1177/030006059502300304; PubMed PMID: 7649341.

17. de Blasio F, Lanata L, Fontana G, Saibene F, Zanasi A. Efficacy of levodropropizine in pediatric and adult population: 2 systematic reviews and meta-analysis of published clinical studies, education, teaching, and quality improvement. Chest. 2014 Oct; 146(4): 526A. DOI: 10.1378/ chest.1991481.

18. Kallesen M. Cough reflex following orotracheal intubation: presence and recovery of the cough reflex after extubation and validity of cough reflex testing. [Internet]. The University of Canterbury. 2016. Available from: http://hdl.handle.net/10092/13001.

19. Divatia JV, Bhowmick K. Complications of endotracheal intubation and other airway management procedures. Indian journal of anaesthesia. 2005 Jan; 49(4):308-318.

20. Song JW, Jang YS, Jung MC, Kim JH, Choi JH, Park S, et al. Levodropropizine-induced anaphylaxis: case series and literature review. The korean academy of asthma, allergy and clinical immunology. Allergy Asthma Immunol Res. 2017 May; 9(3):278-280. DOI: 10.4168/ aair.2017.9.3.278; PubMed PMID: 28293935; PubMed Central PMCID: PMC5352580. 